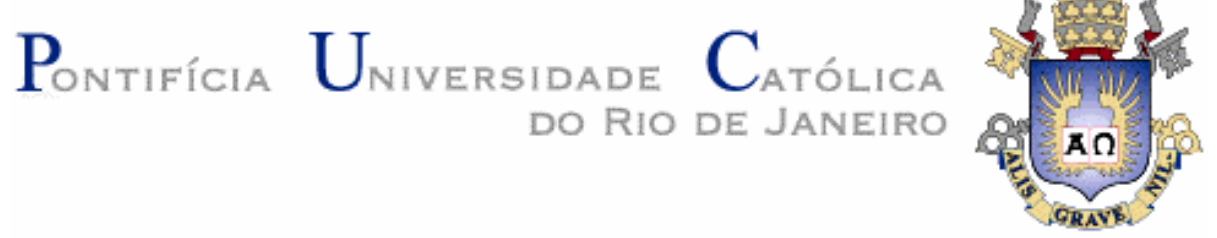

Juliana Maia Vieira

\title{
O palco como espaço de um ideal: o conceito de tragédia na obra de Friedrich Schiller
}

Dissertação de Mestrado

Departamento de Letras

Programa de Pós-Graduação em Letras 


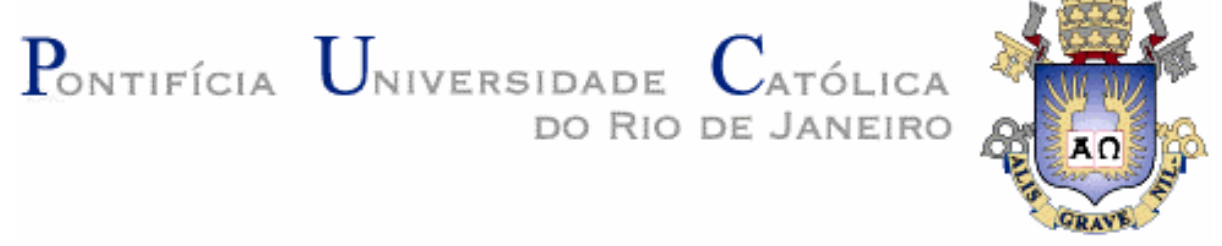

Juliana Maia Vieira

\title{
O palco como espaço de um ideal: o conceito de tragédia na obra de Friedrich Schiller
}

\author{
Dissertação de Mestrado
}

Dissertação apresentada ao Programa de Pós-graduação em Letras da PUC-Rio como requisito parcial para obtenção do título de Mestre em Letras.

Orientador(a): Ana Paula Veiga Kiffer (PUC-Rio) 


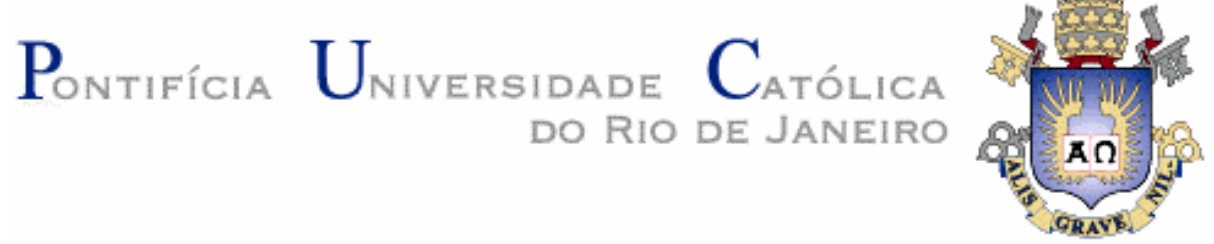

Juliana Maia Vieira

\begin{abstract}
O palco como espaço de um ideal: o conceito de tragédia na obra de Friedrich Schiller
\end{abstract}

Dissertação apresentada como requisito parcial para obtenção do grau de Mestre pelo programa de PósGraduação em Letras do Departamento de Letras do Centro de Teologia e Ciências Humanas da PUC-Rio. Aprovada pela Comissão Examinadora abaixo assinada.

Prof. Dr. Ana Paula Veiga Kiffer Orientador(a)

Departamento de Letras - PUC-Rio

Prof. Dr. Karl Erik Schollhammer Departamento de Letras - PUC-Rio

Prof. Dr. Izabela Maria Furtado Kestler Departamento de Letras - UFRJ

Prof. Paulo Fernando Carneiro de Andrade Coordenador Setorial do Centro de Teologia

e Ciências Humanas - PUC-RIO

Rio de Janeiro, 13 de setembro de 2007 
Todos os direitos reservados. É proibida a reprodução total ou parcial do trabalho sem autorização da universidade, da autora e do orientador(a).

\section{Juliana Maia Vieira}

Graduada em Letras: Português e Literatura pela Pontifícia Universidade Católica do Rio de Janeiro em 2003. Foi, durante todo o curso, bolsista do Programa Especial de Treinamento (PET).

Ficha Catalográfica

Vieira, Juliana Maia

O palco como espaço de um ideal: o conceito de tragédia na obra de Friedrich Schiller / Juliana Maia Vieira; orientadora: Ana Paula Veiga Kiffer. - 2007.

157 f. ; $30 \mathrm{~cm}$

1. Dissertação (Mestrado em Letras)-Pontifícia Universidade Católica do Rio de Janeiro, Rio de Janeiro, 2007.

Inclui bibliografia

1. Letras - Teses. 2. Schiller, Friedrich. 3. Tragédia. 4. Literatura alemã. 5. Estética. 6. Educação estética. I. Kiffer, Ana Paula Veiga. II. Pontifícia Universidade Católica do Rio de Janeiro. Departamento de Letras. III. Título. 


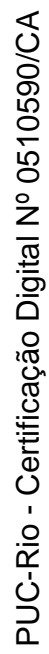

Para minha filha, meu melhor presente. 


\section{Agradecimentos}

Ao CNPq e à PUC-Rio pelos auxílios concedidos para a realização desse trabalho.

A minha orientadora, Ana Paula Kiffer, pela confiança na seriedade do meu trabalho e por aceitar embarcar comigo nessa aventura.

A Izabela Kestler, pela generosidade e por se dispôr a ler meu trabalho.

Ao Karl Erik Schoolhammer, pela disponibilidade e pela atenção de sempre.

A minha filha, pela felicidade de todos os dias.

Ao meu Daniel, pelas cartas inesquecíveis, pelo amor de todo dia, pela paciência nos dias difíceis e pela amizade que foge ao convencional.

A minha mãe, Valtania, pela dedicação incansável, pelo incentivo, pela confiança, por tudo, tudo.

Ao meu pai, in memoriam, por me ensinar a nunca desistir.

A minha irmã, Luciana, pela amizade que resistiu à adolescência.

Aos meus avós, Aurélio e Elisabeth, por serem minha grande saudade.

A Katita, pela presença sempre tão alegre com que tem me acompanhado por todos esses anos.

Aos meus sogros, Airam e Carlos, pelos livros imprescindíveis, pelo carinho com que me receberam e pela constante solicitude. 
As minhas amigas, Cláudia Gonzaga, Joana Beleza, Alyne Oliveira, Karinna Câmara, Clarissa Soares e Tacila Coral, pelos incríveis anos de faculdade, pelas incontáveis gargalhadas, pelo incentivo, pela amizade sincera, pelos chopps, pela importância que têm na minha vida.

A minha amiga Manuela Dias, pelos indescritíveis momentos desses tantos anos.

A minha amiga Mônica Montone, pela luz e pela amizade tão gostosa.

Às meninas do Departamento, Chiquinha, Di e Mirian, por serem meus dois braços em meio a tanta burocracia.

Aos amigos de pós, Luciana Arnaud, Henrique Castilho, Luciana Gattass, Stella Caymmi, Myrtes Follegati, Frederico Coelho, Mauro Gaspar Filho, Leonardo Abreu e Felipe Carvalho, pelas trocas intelectuais.

A Renato Marques, por me apresentar a Schiller. 


\section{Resumo}

Vieira, Juliana Maia; Kiffer, Ana Paula Veiga. O palco como espaço de um ideal: o conceito de tragédia na obra de Friedrich Schiller. Rio de Janeiro, 2007. 157p. Dissertação de Mestrado - Departamento de Letras, Pontifícia Universidade Católica do Rio de Janeiro.

Os conceitos de belo e sublime em Schiller, apoiados numa estética kantiana, conduziram a filosofia para uma possibilidade de educação estética do homem, responsável pela plena liberdade e realização da vontade humanas. Dentro desse panorama, disposto a traçar um caminho de representação na arte dessa liberdade humana, Schiller propõe o conceito de tragédia moderna. Sobre seus fundamentos e sobre o seu propósito de repensar a poética da tragédia se debruçará essa dissertação. Em que medida a tragédia schilleriana é, de fato, capaz de definir o trágico e libertar o homem?

\section{Palavras-chave}

Tragédia; Literatura Alemã; Estética; Educação Estética; Friedrich Schiller. 


\section{Abstract}

Vieira, Juliana Maia; Kiffer, Ana Paula Veiga. The stage as space of an ideal: the notion of tragedy in Friedrich Schiller's work. Rio de Janeiro, 2007. 157p. Rio de Janeiro, 2007. M.A. Dissertation - Letters Department. Pontifícia Universidade Católica do Rio de Janeiro.

Johann Christoph Friedrich von Schiller's conceptions of the beautiful and the sublime - unquestionably influenced by Kantian Aesthetics - have conducted Philosophy to a possibility of aesthetic formation/education of individuals. This possibility has endowed them to attain complete autonomy in regards to their exercise of freedom and free will. It is within this context that Schiller, determined to represent this newfound notion of human autonomy in art, fosters his notion of modern tragedy. It is the purpose of this dissertation to study and scrutinize Schiller's groundings and intent to transform the notion of tragedy. The present investigation shall attempt to answer such questions as till what point is Schillerean tragedy indeed able to define the concept of 'the tragic', and render individuals free?

\section{Keywords}

Tragedy; German Literature; Aesthetic; Aesthetic Education; Friedrich Schiller 


\section{Sumário}

1. Introdução

2. Traços históricos: uma topografia civilizacional

2.1. Construindo a história

2.2. Elementos da civilização

3. Premissas kantianas

3.1. O problema do conhecimento a priori

3.2. Sobre a determinação moral do homem

3.3. A estética kantiana

3.3.1. O fundamento subjetivo do belo

3.3.2. O supra-sensível

61

4. Abordagem schilleriana à estética

67

4.1. O fundamento objetivo do belo

67

4.2. A educação estética

80

4.3. Sobre o sublime

98

5. Schiller e o conceito de tragédia

106

6. Entre a tradição e a modernidade: Schiller e a questão do trágico

6.1. Aristóteles e a tragédia grega

6.2. Condição trágica 
Por vezes à noite há um rosto Que nos olha do fundo de um espelho

E a arte deve ser como esse espelho Que nos mostra o nosso próprio rosto

Jorge Luis Borges, Arte Poética 